\title{
Discovery of Halicyclops continentalis (Cyclopidae, Halicyclopinae) from Estuaries and Salt Marshes on the West Coast of South Korea
}

\author{
Cheon Young Chang* \\ Department of Biological Science, Daegu University, Gyeongsan 712-714, Korea
}

\begin{abstract}
A cyclopoid species from several salt marshes and estuaries on the west coast of South Korea were identified as Halicyclops continentalis Ueda and Nagai, 2009, recently described from Ariake Bay at northwestern Kyushu, Japan. Detailed examination on the Korean specimens justifies Ueda and Nagai's proposition that the $H$. sinensis sensu Tai and Chen, 1979 formerly known from the Chinese coast of the Yellow Sea should be identical to $H$. continentalis. Furthermore, this report reinforces their assumption on the geographical distribution of $H$. continentalis, that is, the Ariake Bay population is a continental relict of the East Asia continent. Herein, a redescription of the species is provided on the basis of the Korean specimens, with a comment on the morphological comparison among three populations around the Yellow Sea.
\end{abstract}

Keywords: brackish Copepoda, distribution, Halicyclops continentalis, taxonomy, Yellow Sea

\section{INTRODUCTION}

Halicyclops is a cosmopolitan cyclopoid genus of the subfamily Halicyclopinae, widely distributed in several kinds of surface brackish water bodies, tidal pools, lagoonal and estuarine coasts, anchialine caves, sinkholes, interstitial and sandy beaches habitats, as well as ponds and marshes (Pesce, 2011). One-hundred-four species or subspecies are recorded in the genus (Walter and Boxshall, 2011). In Korea, seven species of the genus Halicyclops are currently recognized (Chang, 2009).

Recently, Ueda and Nagai (2009) described three new species from Ariake Bay of Kyushu, Japan. In the remarks section of one of their three new species, H. continentalis, they regarded the $H$. sinensis sensu Tai and Chen, 1979 from Chinese coast of the Yellow Sea as being identical to $H$. continentalis.

As ' $H$. sinensis' was also recorded from Korea nearly at the same time (Chang, 2009), a re-examination of the ' $H$. sinensis' formerly reported in Korea is crucial. By a detailed re-examination on Halicyclops specimens originally obtained from 42 localities, which are part of the specimen collection of the Department of Biological Science, Daegu Univer- sity, I found some Korean specimens from the western coast coincided with $H$. continentalis. Moreover, the formerly known ' $H$. sinensis' from Korea is a distinct species from $H$. continentalis as well as $H$. sinensis sensu Tai and Chen, 1979 from China, in having the characteristic spine/seta arrangement on P3-P4 exp 3 by the replacement of a spine with a plumose seta.

Herein, I redescribe $H$. continentalis with detailed illustrations, based on the specimens from the western coast of Korea, because the Korean specimens showed some minor discrepancies in a few details, and this is the first report outside from the type locality. Furthermore, I tried to confirm Ueda and Nagai's proposition (2009) that the H. sinensis sensu Tai and Chen, 1979 is identical to H. continentalis, with brief comments on the intraspecific discrepancies among the three populations.

\section{MATERIALS AND METHODS}

Material examined in the present study was obtained from estuaries and salt marshes in South Korea since August, 1984, and stocked in the Department of Biological Science, Daegu

\footnotetext{
(c) This is an Open Access article distributed under the terms of the Creative Commons Attribution Non-Commercial License (http://creativecommons.org/ licenses/by-nc/3.0/) which permits unrestricted non-commercial use, distribution, and reproduction in any medium, provided the original work is properly cited. pISSN 2234-6953
}

*To whom correspondence should be addressed

Tel: 82-53-850-6454, Fax: 82-53-850-6459

E-mail: cychang@daegu.ac.kr 
University. Samplings were made using a dipnet or a conical plankton net with a $64 \mu \mathrm{m}$ mesh.

Specimens were dissected and mounted in lactophenol on a Cobb slide, after treatment in a solution of $5 \%$ glycerin95\% ethyl alcohol for 1-2 days. Dissection was performed using two needles made from $0.3 \mathrm{~mm}$ diameter tungsten wire by electrolysis. Mounted specimens were observed using a differential interference contrast microscope (Olympus BX51, Japan) equipped with Nomarski optics. Measurements were done using a digital camera equipped to mount on the microscope (Cool SNAP 5.0M; Roper Scientific, USA) and QCapture Pro ver. 5.0 calibration software (Media Cybernetics, USA).

Voucher specimens have been deposited in the National Institute of Biological Resources, Incheon, Korea, and in the specimen room of the Department of Biological Science, Daegu University, Korea.

Morphological terminology follows Huys and Boxshall (1991). The Sewell's style (1949) is adopted for the armature formula of the swimming legs, in which spines are denoted by Roman numerals and setae by Arabic numerals. Abbreviations used in the text and figure legends: A1, antennule; $\mathrm{A} 2$, antenna; $\mathrm{Fu}$, caudal ramus; $\mathrm{L} / \mathrm{W}$, length to width ratio; P1-P5, legs (pereiopods) 1-5; enp 1-3 or exp 1-3, the first to third endopodal or exopodal segments of each leg.

\section{SYSTEMATIC ACCOUNTS}

Order Cyclopoida Burmeister, 1835

Family Cyclopidae Dana, 1846

Subfamily Halicyclopinae Kiefer, 1927

Genus Halicyclops Norman, 1903

\section{1*Halicyclops continentalis Ueda and Nagai, 2009}

(Figs. 1-3)

Halicyclops sinensis: Tai and Chen, 1979: 313, figs. 176, 177. Halicyclops continentalis Ueda and Nagai, 2009: 288, figs. $2,3$.

Material examined. Korea: 3 우 우, Chungcheongnam-do:

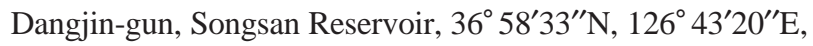
5 May 2010, Chang CY, Lee J; 6 우 우, Dangjin-gun, Songakeup, Bogun-ri, former salt farm, $36^{\circ} 55^{\prime} 22^{\prime \prime} \mathrm{N}, 126^{\circ} 46^{\prime} 50 \mathrm{E}^{\prime \prime}$, 1.5-2.1 psu, Sep, Oct 2010, Moon SD; 4 우 우, Seosan-gun, Palbong waterway, $36^{\circ} 48^{\prime} 48^{\prime \prime} \mathrm{N}, 126^{\circ} 20^{\prime} 08 \mathrm{E}^{\prime \prime}$, $23 \mathrm{Jul} 2009$, Chang CY, Lee J; 2 우 우, Seocheon-gun, detention reservoir at Busa Tidal Embankment, 36 $11^{\prime} 39^{\prime \prime} \mathrm{N}, 126^{\circ} 32^{\prime} 24 \mathrm{E}^{\prime \prime}, 15$ Jul 2003, Chang CY, Lee J.
Description. Female: Body (Fig. 1A) relatively small, mean $683.6 \mu \mathrm{m}$ long (range, 664.2 to $698.4 \mu \mathrm{m}, \mathrm{n}=12$ ), excluding caudal setae; maximum width at posterior end of cephalothorax, $252.8 \mu \mathrm{m}$; L/W about 2.7. Body slightly flattened dorsoventrally. Prosome comprising cephalothorax incorporating first pedigerous somite and 3 free pedigerous somites; posterior margins of prosomites nearly smooth, not serrated; outer distal corners of first three prosomites weakly expanded posteriorly. Cephalothorax strongly protruded anteriorly, so somewhat triangular in general appearance; L/W about 1.1; ellipsoidal integumental window (or median depression) present mid-dorsally; 12-18 sensilla scattered on dorsal and lateral surfaces. Rostral expansion rarely visible from dorsal view. Fifth pedigerous somite incorporating basis and endopod of P5, bearing a basal seta outer posterior corner of dorsal surface. Genital double-somite (Fig. 1A-C) much wider than long (L/W 0.63, at level of lateral expansion); both sides of anterior part expanded laterally, lacking spinous processes; lateral expansion somewhat rectangular in general with its corner not pointed but obtuse or round; in dorsal view, strongly sclerotized wrinkles just ahead lateral expansion armed with 3 appendages representing P6 (Fig. 1B); genital area simple, with a big median copulatory pore anteriorly; with paired cuticular recesses ventrolaterally at posterior half of genital double-somite (Fig. 1C). Mid-dorsal hyaline fringe of preanal somite protruding posteriorly, with 12-15 teeth along posterior margin, slightly not extending over anal operculum (Fig. 1B).

Fu (Fig. 1B) not elongate, about 1.38 times longer than wide; divergent posteriorly; armed with spinules at outer distal margin of ramus and near base of outer caudal seta. Lateral caudal seta lying proximally and dorsally. Inner caudal seta 0.7 times as long as ramus. Outer caudal seta slightly shorter than ramus. Dorsal caudal seta arising from shallow protuberance, 1.5 times longer than ramus. Small cuticular tube with a minute pore present outside the protuberance. Both inner and outer terminal caudal setae with breaking planes; outer terminal caudal seta ornamented heterogeneously on its outer margin: proximal quarter bare, second quarter pinnate, distal half plumose.

A1 (Fig. 2A) not reaching to halfway of cephalothorax; 6segmented. Fourth segment 1.4-1.5 times as long as wide; last segment about 1.9 times longer than wide. Aesthetasc each arising from fourth and last segment distally. Seta formula: 8, 12, 5, 6(+1 aesthetasc), 2, $10(+1$ aesthetasc).

A2 (Fig. 2B) 3-segmented, comprising coxobasis and 2segmented endopod. Coxobasis ornamented with 1 setule row proximally, armed with 2 pinnate inner distal setae, and 1 outer distal seta representing exopod. First endopodal seg-

Korean name: ${ }^{1 *}$ 대륙짠물검물벼룩 (신칭) 

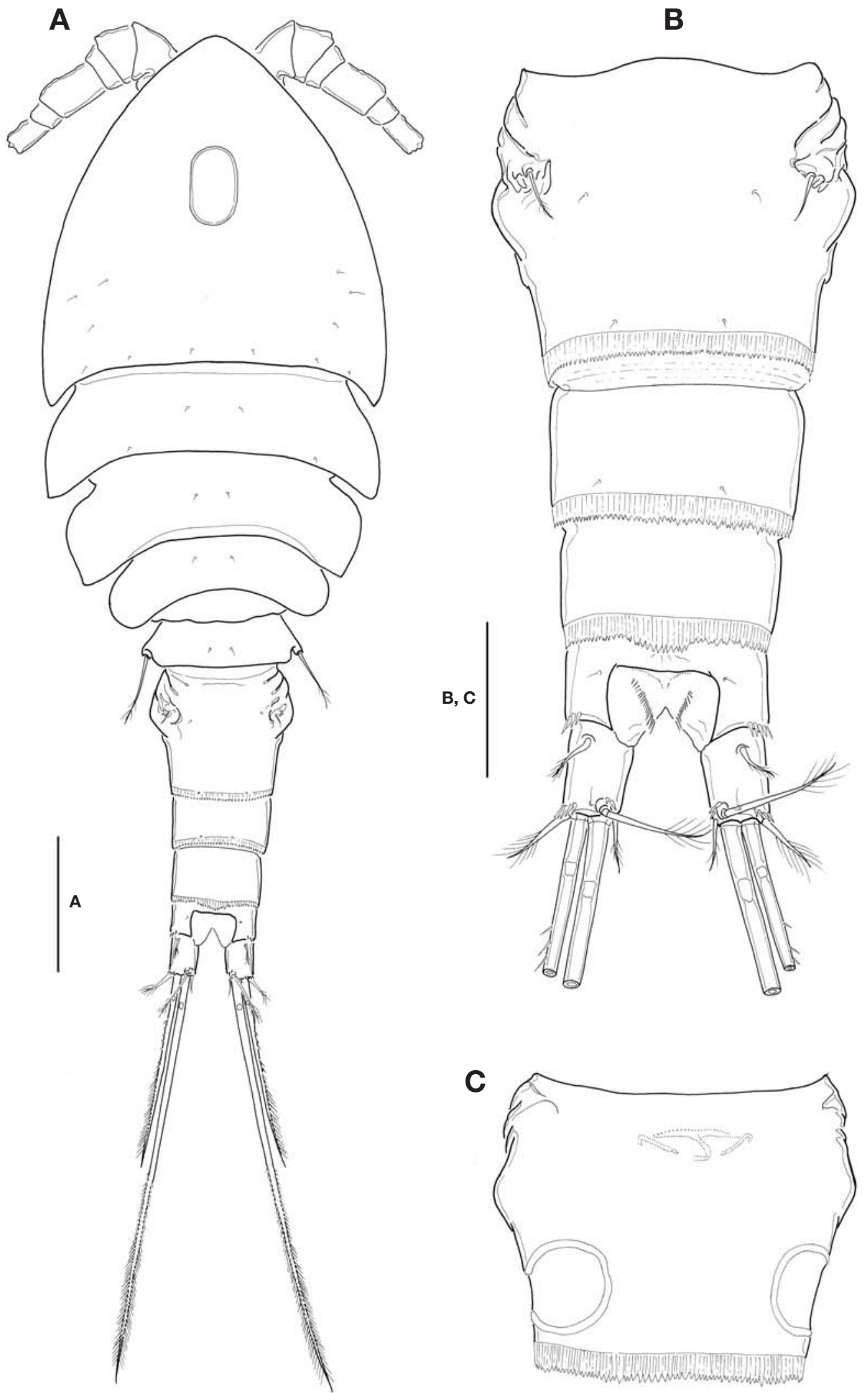

Fig. 1. Halicyclops continentalis Ueda and Nagai, female. A, Habitus, dorsal; B, Urosome, dorsal; C, Genital double-somite, ventral. Scale bars: $A=100 \mu \mathrm{m}, B, C=50 \mu \mathrm{m}$. 


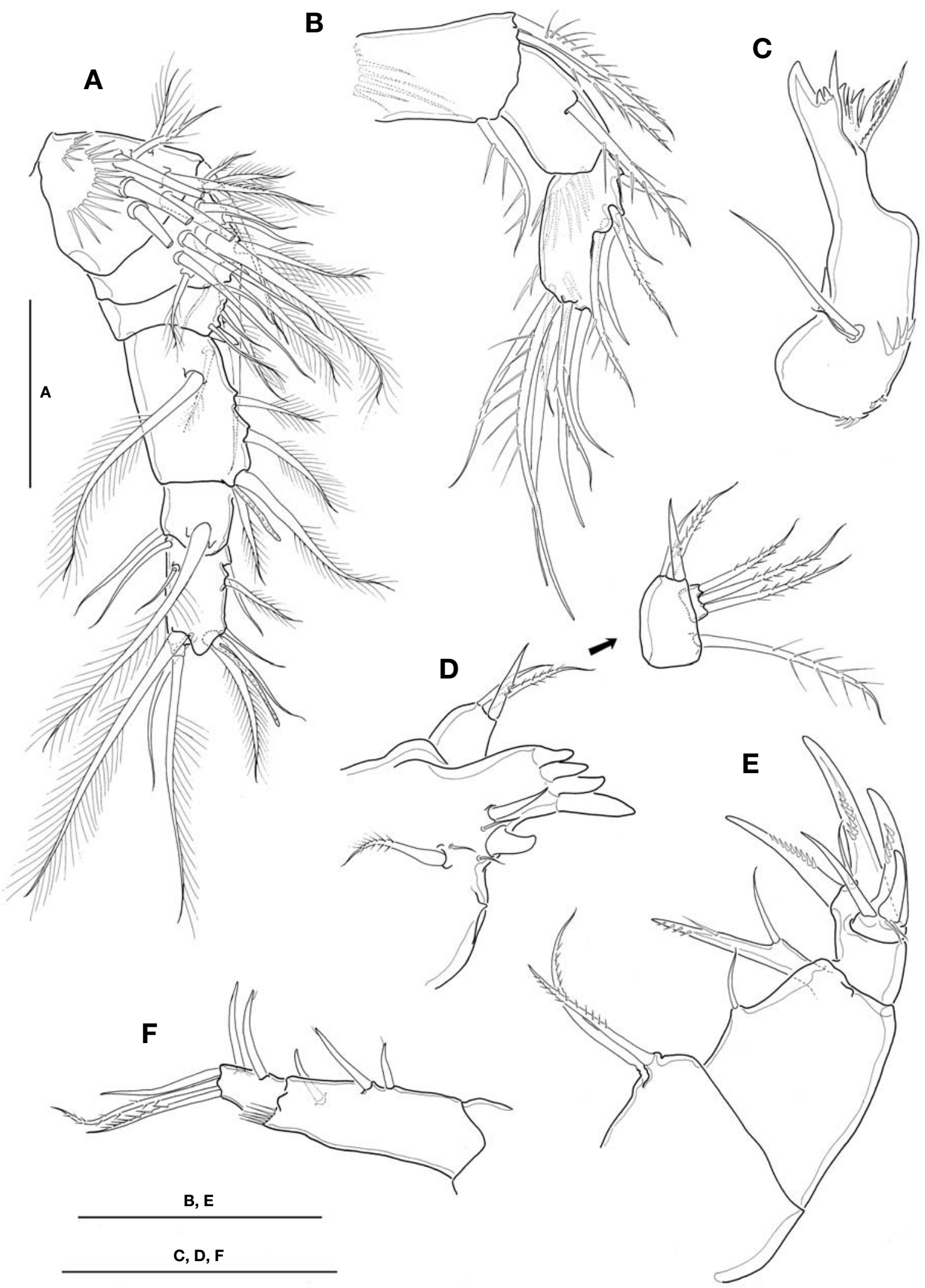

Fig. 2. Halicyclops continentalis Ueda and Nagai, female. A, A1; B, A2; C, Mandible; D, Maxillule; E, Maxilla; F, Maxilliped. Scale bars: $A-F=50 \mu \mathrm{m}$. 


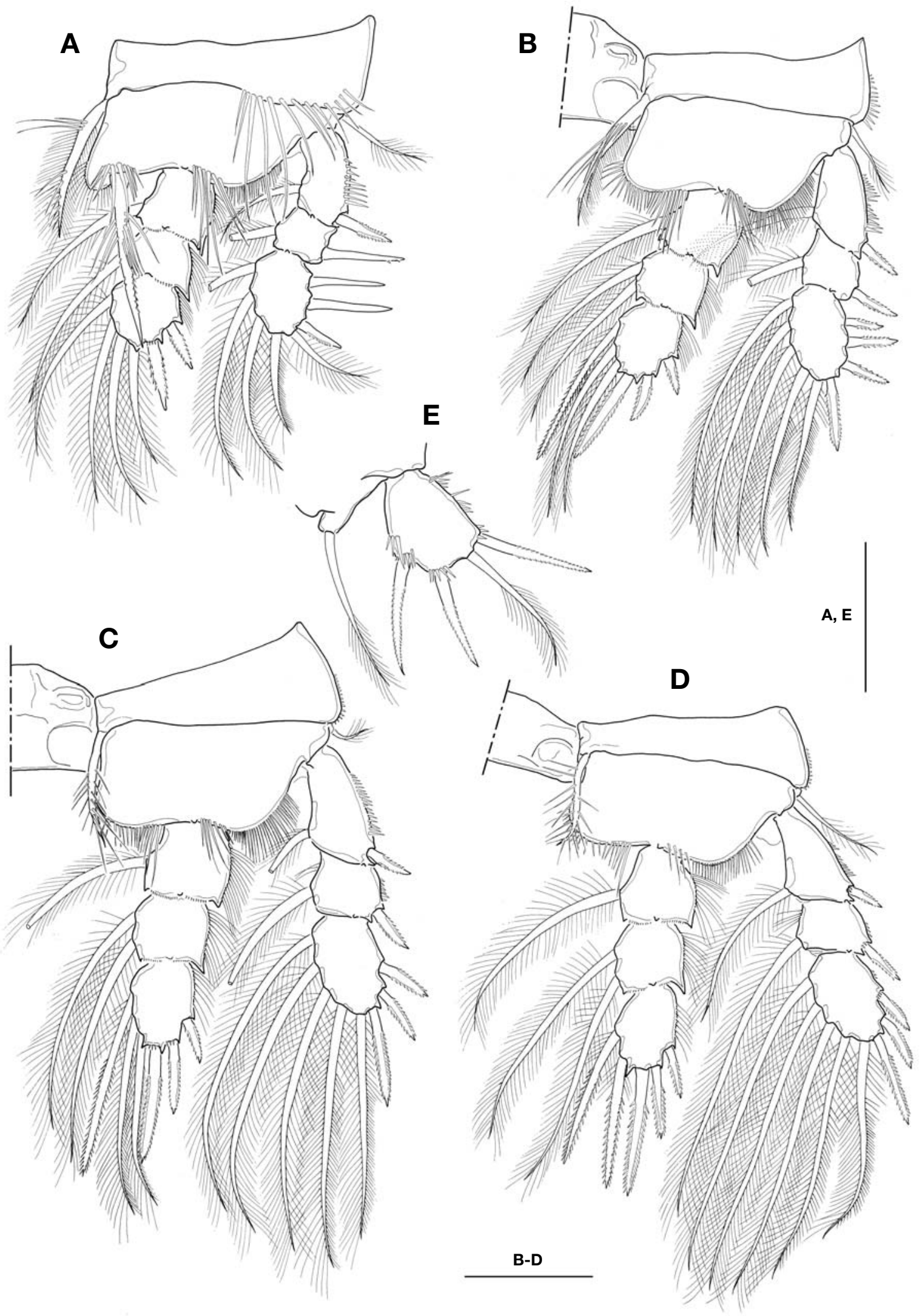

Fig. 3. Halicyclops continentalis Ueda and Nagai, female. A, P1; B, P2; C, P3; D, P4; E, P5. Scale bars: A-E=50 $\mu \mathrm{m}$. 
ment bearing 1 pinnate inner seta, with smooth margins lacking spinules. Second endopodal segment 1.8 times as long as wide, about 1.1 times longer than first endopodal segment; ornamented with 1 spinule row on caudal face proximally; armed with 5 lateral and 7 apical setae.

Mandible (Fig. 2C), with well-developed coxal gnathobase, armed with 6 strong teeth, 4 slender spiniform setae and 1 stout spine along cutting edge, flanking 1 outer distal pinnate seta. Palp very reduced, represented by 2 naked setae on small protuberance, of which shorter one small, about $1 / 3$ times as long as longer one.

Maxillule (Fig. 2D), praecoxal arthrite bearing 4 strong tooth-like spines distally; 7 elements with various shapes present along inner margin, including 1 small proximalmost projection. Palp 2-segmented; coxobasis bearing 1 pinnate and 1 spiniform and 1 naked setae inner distally, plus 1 outer pinnate seta representing exopod; distal segment, representing endopod, with 3 long plumose setae.

Maxilla (Fig. 2E) 4-segmented, comprising praecoxa, coxa, basis and 1-segmented endopod. Praecoxal endite with 2 pinnate setae. Coxa with 1 naked seta representing proximal endite; distal endite movable, forming 1 bisetose lobe completely fused with naked seta proximally. Basis forming 2 strong claw-like spines with 1 naked seta between them basally. Endopod carrying 5 elements of 2 claw-like spines, 1 naked spiniform seta and 2 minute slender setae.

Maxilliped (Fig. 2F) 2-segmented, comprising protopod and completely defined endopod; protopod about 3 times longer than endopod. Protopod with 2 naked spiniform setae proximally and 1 spiniform seta distally, representing endites; 1 setule row present on outer distal corner of protopod. Endopod bearing 5 setae in total, comprising 2 inner setae, 1 apical, 2 subapical pinnate setae.

P1-P4 (Fig. 3A-D) biramous, both rami 3-segmented. Coxal setae stout, pinnate. Spine formula of 3,4,3,3. Seta/spine armature of P1-P4 as follows:

$$
\begin{aligned}
& \text { P1 coxa 0-1 basis 1-1 exp I-1; I-1; III,1,4 } \\
& \text { enp } 0-1 ; 0-1 ; \text { II, } 1,3 \\
& \text { P2 coxa 0-1 basis 1-0 exp I-1; I-1; IV,1,4 } \\
& \text { enp } 0-1 ; 0-2 ; \text { II,I,3 } \\
& \text { P3 coxa 0-1 basis 1-0 exp I-1; I-1; III,1,4 } \\
& \text { enp } 0-1 ; 0-2 ; \text { II,I,3 }
\end{aligned}
$$

P1 (Fig. 3A), intercoxal sclerite with hairs along distal margin of both lateral lobes; inner distal seta on P1 basis stout, ornamented with long setules proximally and secondary spinules distally, and very long, slightly beyond posterior end of enp 3; distal two spines on exp 3 strikingly longer, about 1.8-1.9 times longer than proximal one. P2-P4, intercoxal sclerite bare along distal margin of both lateral lobes; enp 2 with 2 inner setae. P4 enp 3 (Fig. 3D) about 1.7 times longer than wide; both inner setae apparently spiniform, but proximal quarter of each seta retained plumose; apical spine 1.6 times longer than enp 3 , and about 1.8 times longer than outer apical spine.

P5 (Fig. 3E), basis and endopod completely incorporated to fifth pedigerous somite; basal seta inserted on small protuberance arising from dorsolateral corner of somite. Exopod not elongate, about 1.2-1.3 times longer than wide; inner margin nearly straight, ornamented with spinule rows; inner apical spine longest, only 1.2 times as long as exopod, and 1.1 times longer than outermost spine; apical plumose seta 1.3-1.4 times longer than exopod. P6 (Fig. 1B) indistinct, represented by small genital operculum armed with 3 elements of 2 minute spinous projections and 1 long seta.

Male: Unknown.

Ecology. Specimens were collected from marshes with low salinity at the innermost part of reclaimed region, and from a few estuaries discharging into the west coast of Korea.

This species co-occurred with Sinocalanus sinensis (Poppe, 1889), Pseudodiaptomus inopinus Burckhardt, 1913 (Calanoida), Harpacticella itoi Chang and Kim, 1991, Nitocra koreanus Chang, 2007 (Harpacticoida), Paracyclopina nana Smirnov, 1935, Eucyclops roseus Ishida, 2002 (Cyclopoida). Distribution. Japan (Ariake Bay, Kyushu), China (the Yellow Sea coast between Tianjin and Guangzhou), and Korea (the west coast).

Remarks. At present, according to the number of spines on the distal exopodal segments of P1-P4 (spine formula), seven morphological groups of species are pointed out in the genus Halicyclops s. str. (see Pesce, 2011). Among them, this species belongs to the 'group $\mathrm{C}$ ' in showing the spine formula of 3,4,3,3, which discriminates this species from other congeners hitherto known from Korea with the spine formula of $3,4,4,3$. Together with the spine formula, this species has the character combination of angular protuberances on the genital double-somite (while lacking any protuberance, or displaying a spinous process in other congeners) and the characteristic spines on the $\mathrm{P} 1 \exp 3$, of which the proximal two are much longer than the distal one (Ueda and Nagai, 2009). Korean specimens fit well in all these aforementioned diagnostic features. Moreover, they also coincide with the formerly overlooked "microcharacters" (Pesce, 2011), such as morphology of mouthparts, serrate hyaline fringe on the middorsal part of preanal somite, and the shape of inner setae on P4 enp 3 (modification to spiniform setae or not).

The original description did not place weight on the dorsal integumental window (or median depression) on cephalothorax, which has been known in only three species in the genus Halicyclops according to Karanovic (2004: 57). The structure is apparently shown in all Korean specimens as well as in 
Fig. 2A of the original description. Moreover, the inner proximal setae of P2-P3 enp 3 are modified to spiniform as shown in the case of $\mathrm{P} 4$ enp 3 . The above two characters appear to be common in the other two new species from the Ariake Bay, Japan, and the Halicyclops species from Korea, including three undescribed ones (unpublished data). It should be examined and discussed in the future study whether they might be an evolutionary trend in the East Asian species or not.

Korean specimens show minor discrepancies with the original description: (1) lateral expansion is angular in general appearance, but not acute or rather round at its tip (vs. forming nearly angular); (2) Fu is a little more elongate than in the original description (L/W, 1.38 vs. 1.1-1.2); (3) dorsal caudal seta is 1.53 times longer than $\mathrm{Fu}$ (vs. 2.0), and inner caudal seta 0.7 times as long as Fu (vs. about same); (4) the fourth segment of $\mathrm{A} 1$ is relatively long ( $\mathrm{L} / \mathrm{W}, 1.4-1.5$ vs. 1.3); and (5) P5 exopod is a bit elongate (L/W, 1.25 vs. 1.1). The paired cuticular recesses at the ventrolateral part of the posterior half of genital double-somite (cf. Fig. 1C) were not mentioned in the original description and must have been omitted in their Fig. 2C, which was emphasized as one of the decisive characters in the subgenus system by Karanovic (2006, 2008).

Ueda and Nagai (2009) regarded the $H$. sinensis sensu Tai and Chen, 1979 from Chinese coast of the Yellow Sea as being identical to $H$. continentalis. Halicyclops sinensis was described by Kiefer (1928) as a freshwater form from China that was previously, but not definitively, described by Burckhardt (1913) as "H. aequoreus (Fischer, 1860) or a closely related new species" (Ueda and Nagai, 2009). Later, Tai and Chen (1979) reported ' $H$. sinensis' from Chinese coast of the Yellow Sea (from Tianjin to Guanzhou). However, in spite of the insufficiency and inadequacy of their description and figures, 'H. sinensis' sensu Tai and Chen, 1979 evidently differs from the original $H$. sinensis Kiefer, and must be identical to $H$. continentalis, in consideration of the next character combination: the spine formula of 3,4,3,3 (not 3,4,4,3); the characteristic spine arrangements on P1 exp 1 (the proximal two are strikingly longer than the distal one); well developed inner seta of P1 basis, which exceeds beyond the distal margin of P1 enp 3; the stumpy nature of $\mathrm{Fu}$, which is only a little longer than wide; the relatively very short fourth segment of A1, about 1.3-1.4 times as long as wide; P5 exopod is not elongate but rather ovoid, bearing the long inner distal spine; and both inner setae on $\mathrm{P} 4$ enp 3 are spiniform.

In the Ariake Bay, the type locality of this species, three brackish calanoid species (Sinocalanus sinensis, Tortanus derjugini and Acartia ohtsukai) represent continental relicts, which have been isolated from the continental populations and remained restrictedly to the turbid estuaries of Ariake
Bay (Hiromi and Ueda, 1987; Ohtsuka et al., 1995; Ueda and Bucklin, 2006; Sakaguchi et al., 2011). Ueda and Nagai (2009) supposed H. continentalis also might be a continental relict, as suggested in the specific name continentalis, on the ground that this species shows a restricted distribution only in Ariake Bay in Japan, followed with the wide distribution along Chinese coast of the Yellow Sea (as " $H$. sinensis" by Tai and Chen, 1979). So, the present report from the other side of the Yellow Sea, west coast of Korea, must be a discovery reinforcing their assumption on the continental relict.

\section{ACKNOWLEDGMENTS}

I am grateful to Dr. Jimin Lee for her illustration. I am indebted to Prof. Hiroshi Ueda (Kochi University, Japan) for his paper on the three new species of Halicyclops from the Ariake Bay, Kyushu, Japan. I thank Dr. Chad Walter for providing lots of references. I also appreciate two anonymous reviewers for their critical comments that greatly improved the manuscript. This work was supported in part by the research grant of Daegu University, Korea in 2008.

\section{REFERENCES}

Burckhardt G, 1913. Wissenschaftliche Ergebnisse einer Reise um die Erde von M. Pernod und C. Schröter. III. Zooplankton aus ost- und südasiatischen Binnengewässern. Zoologische Jahrbücher, Abteilung für Systematik, Ökologie und Geographie der Tiere, 34:341-472.

Chang CY, 2009. Illustrated Encyclopedia of Fauna and Flora of Korea. Vol. 42. Inland-water Copepoda. Jeonghaengsa Publ. Co., Seoul, pp. 1-687.

Hiromi J, Ueda H, 1987. Planktonic calanoid copepod Sinocalanus sinensis (Centropagidae) from estuaries of Ariake-kai, Japan, with a preliminary note on the mode of introduction from China. Proceedings of the Japanese Society of Systematic Zoology, 35:19-26.

Huys R, Boxshall GA, 1991. Copepod evolution. The Ray Society, London, pp. 1-468.

Karanovic T, 2004. Subterranean Copepoda from arid western Australia. Crustaceana Monographs, 3. Brill, Leiden, pp. 1366.

Karanovic T, 2006. Subterranean copepods (Crustacea, Copepoda) from the Pilbara region in Western Australia. Records of the Western Australian Museum, Supplement, 70:1-239.

Karanovic T, 2008. Marine interstitial Poecilostomatoida and Cyclopoida (Copepoda) of Australia. Crustaceana Monographs, 9. Brill, Leiden, pp. 1-332.

Kiefer F, 1928. Beiträge zur Copepodenkunde, VII. Zoologischer Anzeiger, 75:216-223. 
Ohtsuka S, Ueda H, Lian GS, 1995. Tortanus derjugini Smirnov (Copepoda: Calanoida) from the Ariake Sea, western Japan, with notes on the zoogeography of brackish-water calanoid copepods in East Asia. Bulletin of the Plankton Society of Japan, 42:147-162.

Pesce GL, 2011. Cyclopoida: Halicyclopinae Kiefer, 1927: Halicyclops A. M. Norman, 1903 [Internet]. Accessed 12 Oct 2011, <http://www.luciopesce.net/ copepods/halicyc.htm>.

Sakaguchi SO, Ueda H, Ohtsuka S, Soh HY, Yoon YH, 2011. Zoogeography of planktonic brackish-water calanoid copepods in western Japan with comparison with neighboring Korean fauna. Plankton Benthos Research, 6:18-25.

Sewell RBS, 1949. The littoral and semi-parasitic Cyclopoida, the Monstrilloida and Notodelphyoida. The John Murray Expedition, 1933-34, Scientific Report, 9:17-199.

Tai AY, Chen GX, 1979. Cyclopoida Sars, 1886. In: Fauna Sinica, Crustacea, Freshwater Copepoda (Ed., Shen CJ). Science
Press, Peking, pp. 301-420.

Ueda H, Bucklin AC, 2006. Acartia (Odontacartia) ohtsukai, a new brackish-water calanoid copepod from Ariake Bay, Japan, with a redescription of the closely related A. pacifica from the Seto Inland Sea. Hydrobiologia, 560:77-91.

Ueda H, Nagai H, 2009. Three new species of the brackishwater copepod Halicyclops (Crustacea, Cyclopoida) from Ariake Bay, Japan. Journal of Natural History, 43:287-307.

Walter TC, Boxshall G, 2011. World Copepoda database [Internet]. World Register of Marine Species, Accessed 12 Oct 2011, <http:// www.marinespecies.org/aphia.php?p= taxdetails\&id=106433>. 